\title{
Sodium Tripolyphosphate and Polyphosphate as Dispersing Agents for Alumina Suspensions: Rheological Characterization
}

\author{
L. Piani and A. Papo \\ Dipartimento di Chimica, Fisica e Ambiente, Università degli Studi di Udine, Via del Cotonificio 108, 33100 Udine, Italy \\ Correspondence should be addressed to L. Piani; luciano.piani@uniud.it
}

Received 24 January 2013; Accepted 29 May 2013

Academic Editor: Paul Luckham

Copyright (C) 2013 L. Piani and A. Papo. This is an open access article distributed under the Creative Commons Attribution License, which permits unrestricted use, distribution, and reproduction in any medium, provided the original work is properly cited.

\begin{abstract}
In the present work, the influence of addition of some dispersing agents employed for maximizing the solid loading of alumina concentrated suspensions has been investigated. Two commercially available deflocculants were used: a sodium tripolyphosphate and a sodium polyphosphate. Rheological tests were carried out at $25^{\circ} \mathrm{C}$ under continuous flow conditions by using the ratecontrolled coaxial cylinder viscometer Rotovisko-Haake 20, system M5-osc., measuring device SV2P with serrated surfaces. The application of rheological techniques permitted the evaluation of the efficiency and the optimum dosage of the dispersing agents employed upon the alumina slips examined, that is, the critical concentration at which the maximum reduction in viscosity is detected.
\end{abstract}

\section{Introduction}

Alumina is widely used in a lot of industrial applications which presuppose the employment of concentrated suspensions. For the preparation of ceramic suspensions by means of techniques such as slip casting and tape casting, submicronsized ceramic powders are needed. Since their flow characteristics are usually of crucial importance, they have to be controlled in order to yield a final product with the best properties as well as to improve the economics of the process and to optimise energy requirements. In general, the rheological behavior of concentrated suspensions is strongly affected not only by solid loading, particle morphology, and particle size distribution but also by particles interactions, which in their turn are dependent of chemical factors, that is, of $\mathrm{pH}$ and/or addition of dispersing agents.

Since very fine ceramic particles spontaneously agglomerate owing to attractive van der Waals forces, they must be dispersed in liquid phase using suitable dispersing agents. The addition of dispersants to suspension can modify their rheological behavior by reducing or enhancing the attractive forces among particles, thus producing dispersion or aggregation, respectively. Generally, suspensions can be dispersed by electrostatic stabilization mechanism; moreover, the employment of oligomeric or polymeric dispersants induces a mechanism of steric stabilization, which is superimposed to the electrostatic one; here, reference is made of Napper [1] and Cesarano and Aksay $[2,3]$. The addition of dispersants to alumina suspensions induces particle repulsion and hence a viscosity decrease until the saturation adsorption limit of dispersing agent is reached; this phenomenon takes place in correspondence to a critical dispersant concentration (optimum dosage) at which electrostatic or electrosteric stabilization occurs. At the optimum dosage, all of the dispersants is virtually adsorbed, and there are negligible amount of free deflocculant remaining in the continuous phase: the slurry shows the minimum viscosity value. Past the adsorption saturation limit, a further addition of dispersant leads to excess deflocculant in the solution, which is not adsorbed on the suspended particles, thus bringing about destabilization, flocculation, and, therefore, an increase of suspension viscosity.

The present work is aimed at studying the influence of the addition of a sodium tripolyphosphate and a sodium polyphosphate on the flow characteristics of suspensions prepared with an alumina powder of high purity.

There is a significant amount of scientific literature on alumina suspensions rheology. In this paper, a mention is made of some of the most recent articles: De Vasconcelos et al. [4], Lu and Kessler [5], Papo and Piani [6], Pradhan and Bhargava [7], and Tomasik et al. [8]. 
TABLE 1: Description of the alumina powder employed.

Trade name: High Purity Alumina AKP-15 by Sumitomo Chemical Co. Ltd. (Japan)

Crystal form: $\alpha-\mathrm{Al}_{2} \mathrm{O}_{3}$

Purity: > 99.99\%

Mean particle size: $0.68 \mu \mathrm{m}$

Particle size distribution $<1 \mu \mathrm{m}: 83 \%$

Loose bulk density: $0.9 \mathrm{~g} / \mathrm{cm}^{3}$

Tapped bulk density: $1.3 \mathrm{~g} / \mathrm{cm}^{3}$

BET specific surface area: $3.8 \mathrm{~m}^{2} / \mathrm{g}$

Impurity analysis: Si 22 ppm; $\mathrm{Na} 5$ ppm; $\mathrm{Mg} 6$ ppm; $\mathrm{Cu}<1$ ppm;

Fe 19 ppm

Sodium tripolyphosphate and sodium polyphosphate are anionic inorganic dispersants. Inorganic dispersants have attracted great attention as ceramic processing aids because the surfactants themselves can be incorporated into the ceramic matrix (Exarhos et al. [9]). When organic surfactants are used in the colloidal ceramic processing (mixing, dispersing, and forming) stages, they have to be removed later by thermal decomposition. This process causes materials to shrink and generates gaseous wastes. The inorganic dispersants as an alternative processing aid will eliminate or reduce these problems because the majority of the inorganic surfactants will be converted to ceramic materials.

\section{Experimental Methodology}

2.1. Materials. The suspensions were prepared with a vane stirrer (Ultra-Turrax T50, Janke \& Kunkel, IKA-Labortechnik) from deionized water and an alumina powder of high purity, whose characteristics supplied by producer are reported in Table 1 .

Plain suspensions with increasing solid content were prepared starting from $62.5 \mathrm{wt} \%$ of alumina. At last $77.5 \mathrm{wt} \%$ was found to be the highest solid content of alumina in the suspension that can be loaded into the viscometric cup without deflocculant (the highest measurable viscosity referred to our rheometer has been taken as reference).

Two commercial condensed phosphates were tested as potential dispersing agents for alumina suspensions on account of their satisfactory dispersing capacity and low cost: a sodium tripolyphosphate $\left(\mathrm{P}_{2} \mathrm{O}_{5} / \mathrm{Na}_{2} \mathrm{O}=0.6\right.$; molecular weight $=367.86$; in the following: TPP) and a sodium polyphosphate (commercial name: hexametaphosphate) $\left(\mathrm{P}_{2} \mathrm{O}_{5} / \mathrm{Na}_{2} \mathrm{O}=0.9\right.$; average molecular weight $=1733.39$; in the following: PP) by Sigma-Aldrich. Both dispersants were employed within a large range of concentration (0.005 to $1 \mathrm{wt} \%$ ) and were added to a $77.5 \mathrm{wt} \%$ aqueous alumina suspension.

2.2. Apparatus and Procedures. Rheological measurements were carried out using the rate-controlled coaxial cylinder viscometer Rotovisko-Haake 20, system M5-Osc., measuring device SV2P with serrated surfaces. The temperature was kept

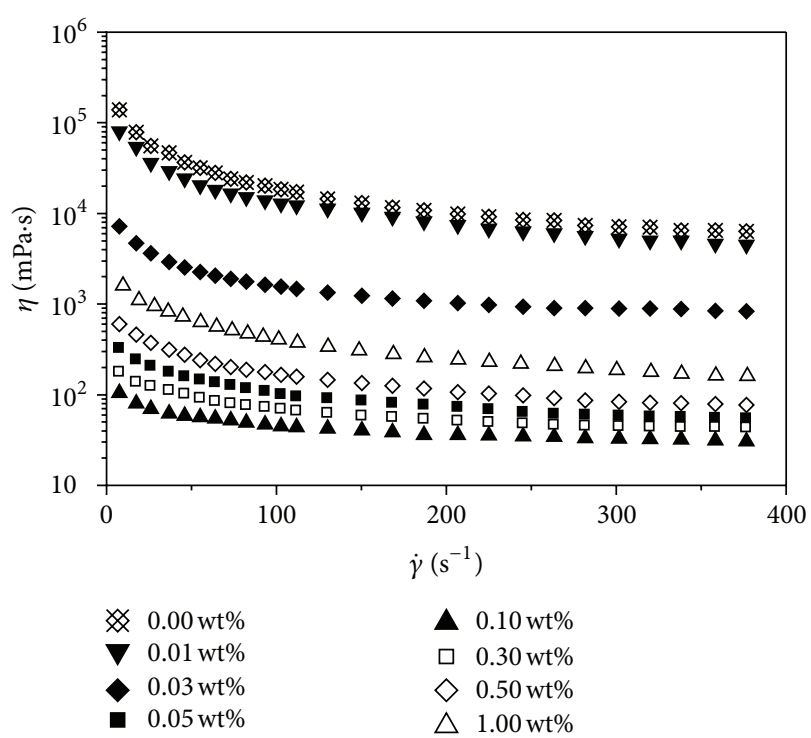

Figure 1: Apparent viscosity $(\eta)$ versus shear rate $(\dot{\gamma})$ flow curves for the $77.5 \mathrm{wt} \%$ alumina + sodium tripolyphosphate suspensions studied.

strictly constant at $25.0 \pm 0.1^{\circ} \mathrm{C}$. Flow curves were drawn under continuous flow conditions by changing the shear rate from 0 to $389 \mathrm{~s}^{-1}$ at the $3.24 \mathrm{~s}^{-2}$ constant shear acceleration; each suspension was initially sheared at a high constant shear rate in order to suppress the previous rheological history of the sample tested. Each sample was analyzed in duplicate; each determination was repeated twice.

\section{Results and Discussion}

Concentrated alumina suspensions clearly show non-Newtonian flow characteristics. Time-dependent effects under continuous shearing conditions were negligible with alumina suspensions added with deflocculants. A rather good superposition of up and down curves was observed in the whole range of deflocculant concentration. Hence, in the present work, attention has been essentially focused on the sheardependent behavior of the slips studied.

Figures 1-2 report the apparent viscosity $(\eta)$ versus shear rate $(\dot{\gamma})$ flow curves obtained for the alumina slips investigated.

From examination of the curves, we can state that the addition of either dispersant does not modify the rheological behavior of plain suspension within all the deflocculant concentration range examined but, on the other side, produces a viscosity collapse made evident by adding a slight amount of deflocculant. Viscosity then decreases until reaching optimum dosage where the slurry shows the minimum viscosity value. Any further addition of dispersant leads to an increase of suspension viscosity. Between the dispersants employed, PP shows the more effectiveness (see Figures 1-3), because it produces a viscosity collapse at lower concentration with respect to TPP. 


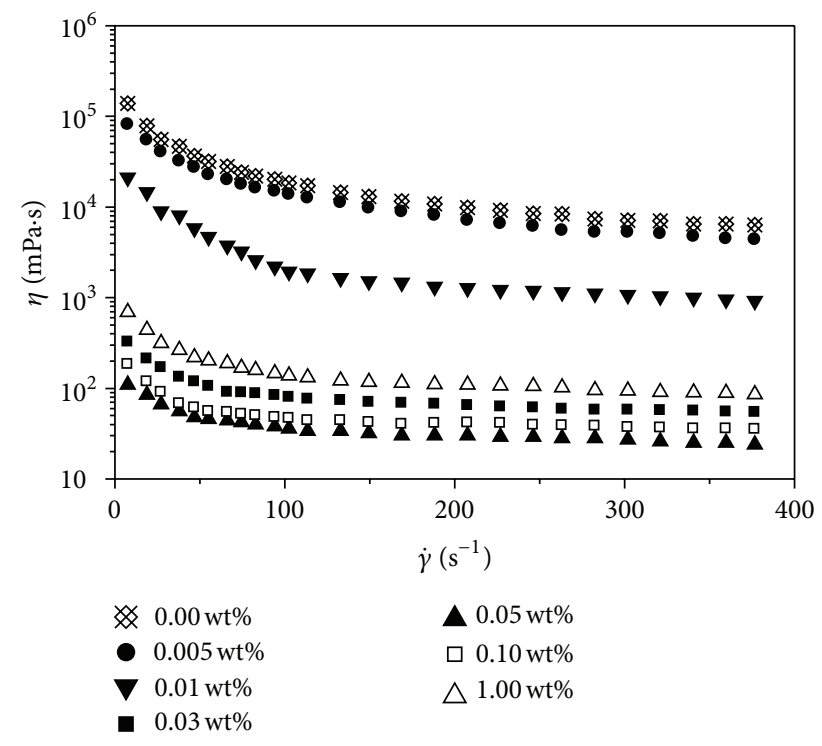

FIGURE 2: Apparent viscosity $(\eta)$ versus shear rate $(\dot{\gamma})$ flow curves for the $77.5 \mathrm{wt} \%$ alumina + sodium polyphosphate suspensions studied.

Moreover, PP shows lower optimal dosage $(0.05 \mathrm{wt} \%)$ than TPP $(0.10 \mathrm{wt} \%)$. However both dispersants do not exhibit a large stabilization range of concentrations beyond optimum dosage but give rise into the suspension to a gradual increase of viscosity becoming sharper only with TPP above $0.30 \mathrm{wt} \%$ of concentration.

TPP and PP dispersing mechanisms in alumina suspensions are determined by interactions between their ionised molecules and surface of alumina particles. The negatively charged phosphate ions are adsorbed at the alumina surface sites through hydrogen bonding. This produces a negative charge on the particles and electrostatic repulsion that causes the decrease of viscosity in the suspension. However, only pure electrostatic repulsion cannot explain the decrease of viscosity, but a steric effect associated with the dispersant chain length must be considered.

Sodium polyphosphate is a polymetaphosphate and has linear chain conformation. PP, which obviously has longer chain than TPP, is bound to the particle surface through the end groups, and most of the middle-chain regions do not participate in the bonding (Liu et al., [10]). This implies that negatively charged PP chains extend from the particle out into the solution and provide the additional steric repulsion forces. Therefore, the stabilization of alumina suspensions can be best described by electrosteric interactions (higher in PP rather than in TPP), thus justifying the better effectiveness of PP between phosphate dispersants here employed.

\section{Conclusions}

Alumina concentrated suspensions examined show a shearthinning behavior. Shear-thinning behavior does not change in the presence of the dispersants (sodium polyphosphate and sodium tripolyphosphate) that have been used in this work.

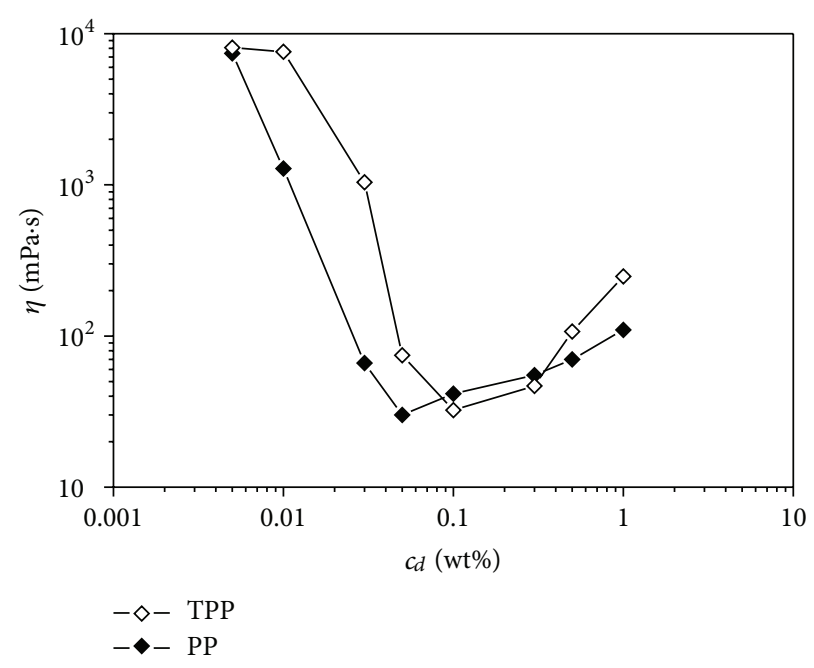

FIGURE 3: Apparent viscosity $(\eta)$ versus deflocculant concentration $\left(c_{d}\right)$ for $77.5 \mathrm{wt} \%$ alumina suspension as function of the dispersant nature $\left(\dot{\gamma}=200 \mathrm{~s}^{-1}\right)$.

Between the dispersants adopted, PP seems to be the more effective dispersing agent for the alumina slips investigated because it exhibits the higher efficiency (collapse in viscosity) at lower concentration with respect to the other deflocculant employed.

Nevertheless, an optimum dosage can be found for both dispersants adopted. The lower optimum dosage evidenced by sodium polyphosphate can be ascribed to a substantial steric contribution due to the adsorbed polyphosphate molecules which form in solution oligomeric chains. On the other side, both dispersants do not give rise to any appreciable stabilization range of concentrations after reaching the deflocculant adsorption saturation (optimum dosage).

\section{Symbols}

$c_{d}$ : Deflocculant concentration, wt $\%$.

\section{Greek Letters}

$\dot{\gamma}$ : Shear rate, $\mathrm{s}^{-1}$

$\eta$ : Apparent viscosity, mPas.

\section{References}

[1] D. H. Napper, Polymeric Stabilization of Colloidal Dispersions, Academic Press, London, UK, 1983.

[2] J. Cesarano III, I. A. Aksay, and A. Bleier, "Stability of aqueous $\alpha$ $\mathrm{Al}_{2} \mathrm{O}_{3}$ slurry with poly (methacrylic acid) polyelectrolyte," Journal of the American Ceramic Society, vol. 71, no. 4, pp. 250-255, 1988.

[3] J. Cesarano III and I. A. Aksay, "Processing of highly concentrated aqueous $\alpha$-alumina suspensions stabilized with polyelectrolytes," Journal of the American Ceramic Society, vol. 71, no. 12, pp. 1062-1067, 1988.

[4] C. L. de Vasconcelos, T. N. C. Dantas, M. R. Pereira, and J. L. C. Fonseca, "Rheology of concentrated alumina-polyelectrolyte 
systems," Colloid and Polymer Science, vol. 282, no. 6, pp. 596601, 2004.

[5] K. Lu and C. Kessler, "Colloidal dispersion and rheology study of nanoparticles," Journal of Materials Science, vol. 41, no. 17, pp. 5613-5618, 2006.

[6] A. Papo and L. Piani, "Rheological properties of alumina slurries: effect of deflocculant addition," Particulate Science and Technology, vol. 25, no. 4, pp. 375-380, 2007.

[7] M. Pradhan and P. Bhargava, "Influence of sucrose addition on rheology of alumina slurries dispersed with a polyacrylate dispersant," Journal of the American Ceramic Society, vol. 88, no. 4, pp. 833-838, 2005.

[8] P. Tomasik, C. H. Schilling, R. Jankowiak, and J.-C. Kim, "The role of organic dispersants in aqueous alumina suspensions," Journal of the European Ceramic Society, vol. 23, no. 6, pp. 913919, 2003.

[9] G. J. Exarhos, K. F. Ferris, D. M. Friedrich, and W. D. Samuels, "Atomic and molecular processing of electronic and ceramic materials: preparation, properties, and characterization," in Proceedings of the Materials Research Society, pp. 127-134, Materials Research Society, Pittsburg, PA, USA, 1988.

[10] J. Liu, L.-Q. Wang, W. D. Samuels, and G. J. Exarhos, "Aggregation and dispersion of colloidal suspensions by inorganic surfactants: effect of chemical speciation and molecular conformation," Journal of Physical Chemistry B, vol. 101, no. 41, pp. 82648269, 1997. 

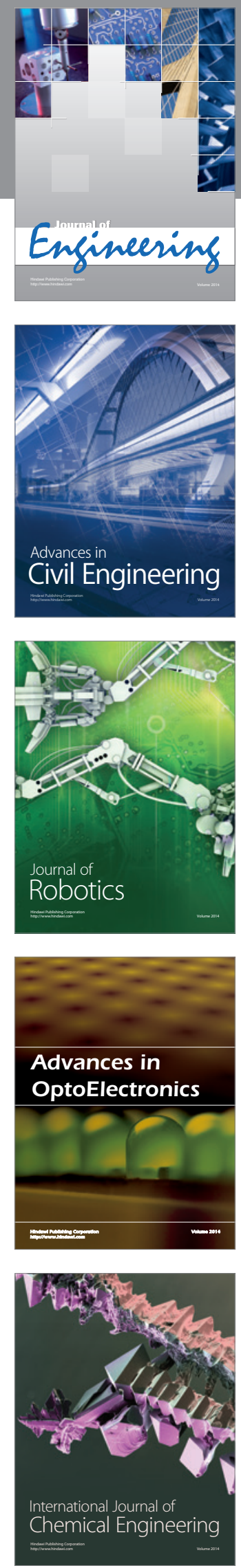

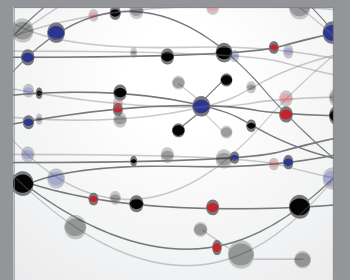

The Scientific World Journal
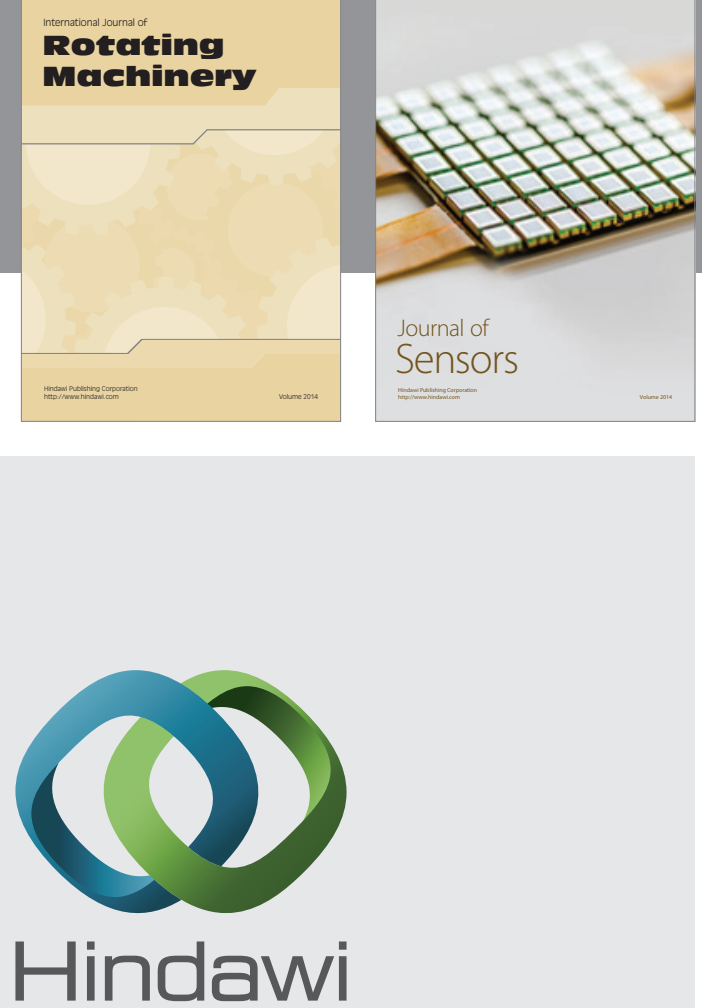

Submit your manuscripts at http://www.hindawi.com
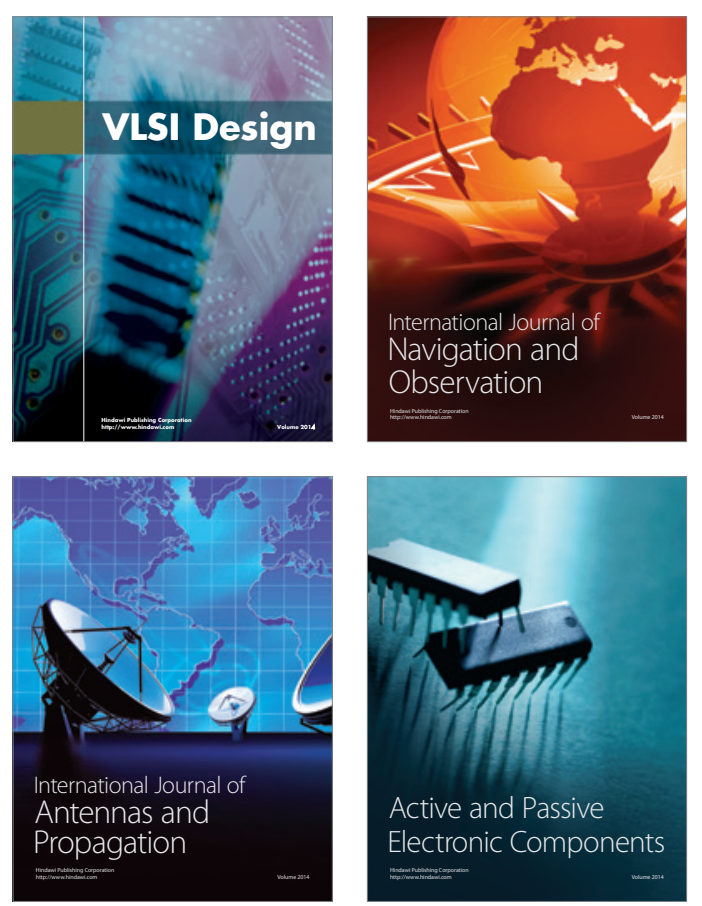
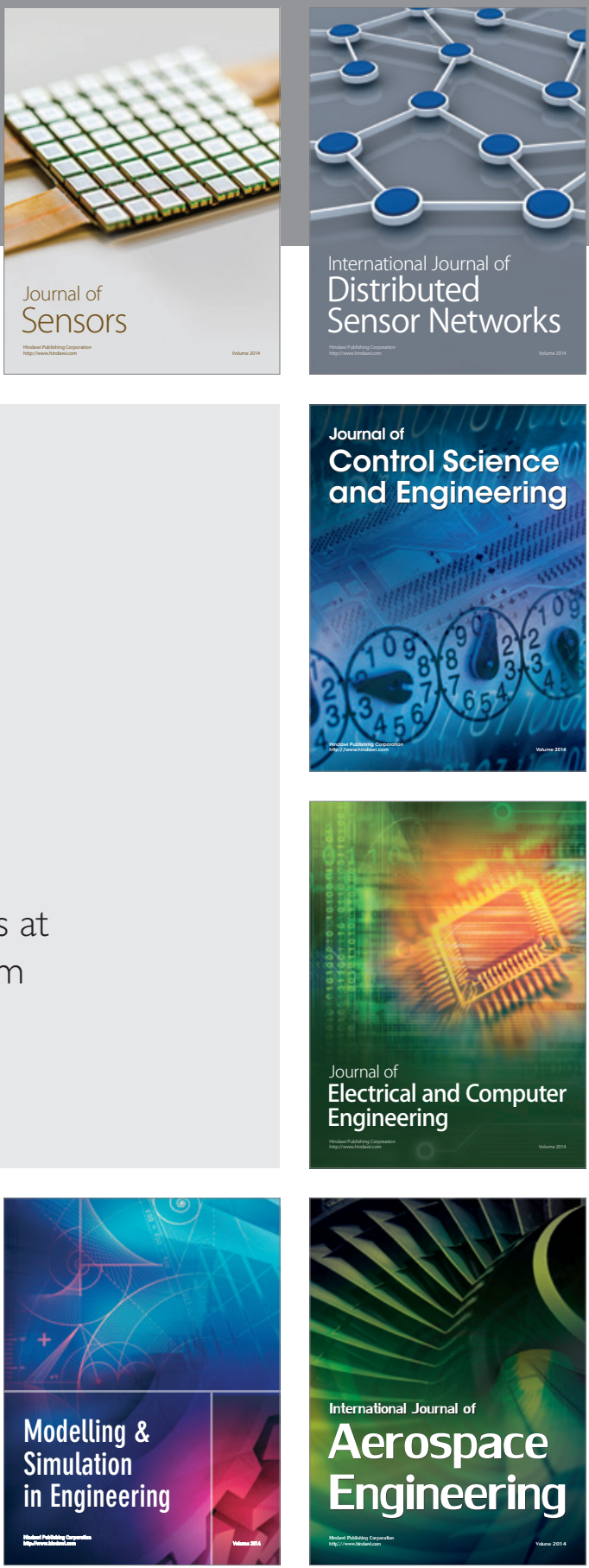

Journal of

Control Science

and Engineering
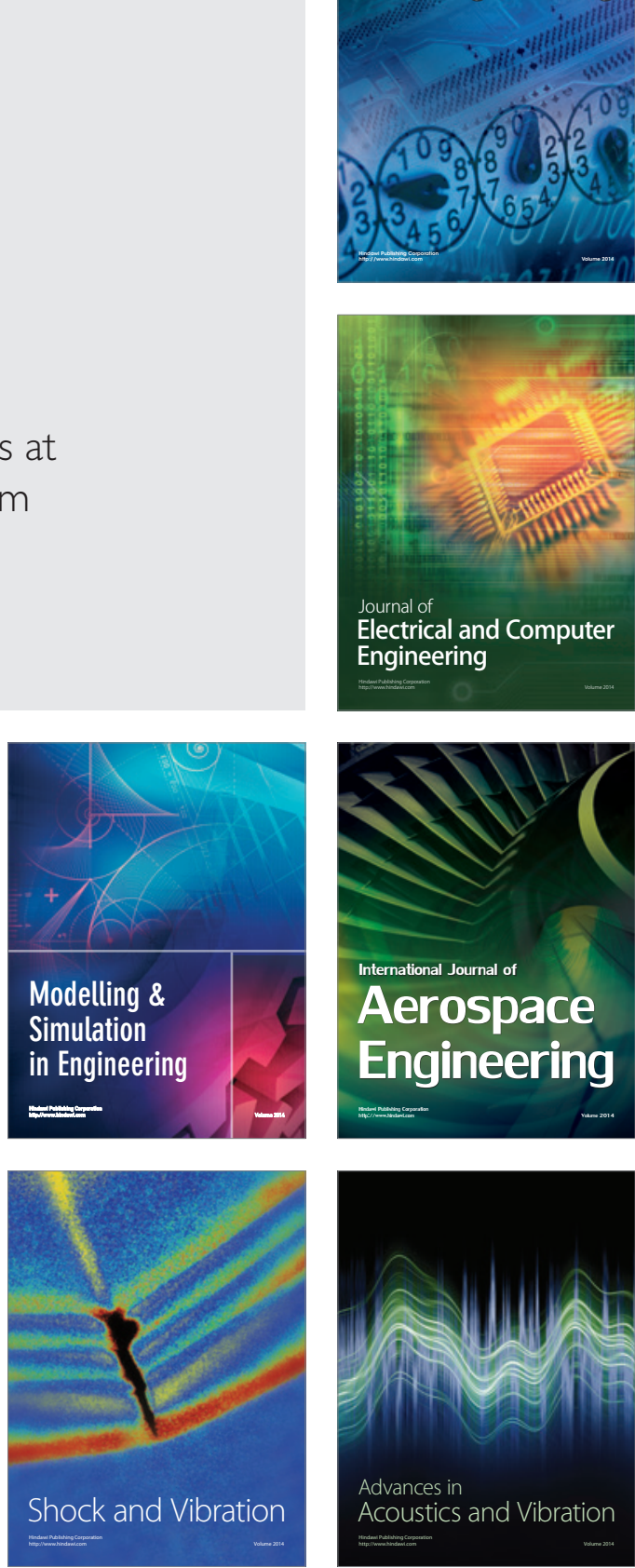